\title{
Research on Perceived Profiles and Stages of Exercise Behavior Change in Urban Residents
}

\author{
Xinyan Guo \\ Business School, Sichuan University, Chengdu610041, China \\ Sindy90story@163.com
}

\begin{abstract}
Keywords: Exercise Behavior, Stages of Change, Exercise Benefits, Exercise Barriers, Urban Resident
\end{abstract}

\begin{abstract}
By means of the Phrasal Change Theory Scale of Stage of Change Theory and the Exercise Benefits and Barriers Scale of Health Belief Model, data were collected on 320 urban residents. Through using the method of literature consultation and mathematical statistics, this paper analyzes the perception of exercise benefits and barriers in urban residents, along with the relativity with different exercise stages. The research results show below: a) These samples either agreed or strongly agreed with most of the benefit items, reflecting that they felt adequate cognizance about benefits of regular exercising, although they have not exclusively participant exercise activity. b) These samples fairly agreed with many of the barrier items, this is consistent with suggestion that perceived barriers could be more influential on behavior than perceived benefits. c) The external factor such as exercise milieu could change exercise behavior in the short-time, not a long-term effect, but the internal factor or extrinsic motivation played an important part in changing and maintaining behavior. And some way of thinking and suggestion to step in exercise intervention was given.
\end{abstract}

\section{Introduction}

The benefits of regular physical exercise to one's physical and mental health are well documented. However, despite these benefits are recognized, it is not easy to engage in exercise sufficiently. Domestic researches (Tang \& Cong, 2009) showed that a lot of residents are aware of the profits of exercises, but many of them haven't built clear exercise consciousness and voluntary exercise habits, which have different degrees of influences on their health quality[1]. Understanding why individuals do not participate in regular exercise activity is complex; there are many reasons for this phenomenon, such as interpersonal causes, cultural effects environmental causes, policy determinants, and so on[2]. Some investigation showed that the female who perceived more benefits from exercise and fewer barriers to exercise were typically more active than those who reported high perceived barriers and low perceived benefits (Nahas \& Goldfine, 2003). These findings are consistent with the research from Lovell and Ansari(2010)and Parker.(2010) [3,4].

To date, the strategies to improve exercise activity in adult do not work. The purpose of this research is, firstly, to examine the perceived exercise benefits and barriers of urban resident's adults. Secondly, this research aims to explore the relationship between perceived benefits/barriers and the stages of exercise behavior change, which indicate the process of the adoption and maintenance of a behavior.

\section{Methods}

Participants. Participants were four hundred and fifty urban residents who were randomly selected from the north and south in China. The people completed a self-administered questionnaire during specially arranged times in groups of 20 to 50 as part of a research participation requirement. Participants who did not complete data were excluded, so 320 adults aged 18 or older, and the mean age of the sample was 42.5 years ( $\mathrm{SD}=3.2$ ), $60.6 \%$ were female, and the effective respondent rate is 91.4\%. Their occupations are full-time workers 51.2\%, part-time worker 9.7\%, retired persons 
$10.1 \%$, housewives $13.8 \%$, students $4.7 \%$, and others $10.5 \%$. About $65 \%$ approached did not meet the regular exercise guideline (ACSM guideline).

Instruments. The study was quantitative, with data gathered through standardized self-report questionnaires. These questionnaires examined the exercise behavior of urban resident's adults. The instruments were the same for all participants. Each questionnaire packet contained the exercise benefits and barriers sale (EBBS. Sechrist, Walker \& Pender, 1987) and stages of change for exercise behavior questionnaire (Oka et al. 2003). The EBBS questionnaire comprised two components: Benefits and Barriers, and the benefits included 29 items categorized into five subscales: life enhancement (8 items), physical performance (8 items), psychological outlook (6 items), social interaction (4 items), and preventative health (3 items). The barrier component included 14 items categorized into four subscales: exercise milieu (6 items), time expenditure (3 items), physical exertion (3 items), and family discouragement (2 items). About the scale of the exercise change, which consists of five items measuring actual exercise behavior performed both in the past and present time, and the condition of readiness to those exercise behaviors (Nigg \& Riebe, 2002).

Data Analysis. All statistical analyses applied in this study were performed using SPSS v 16.0. Frequency analysis was initially conducted to examine the perceived benefits and barriers distribution of adult urban residents. The direct discriminate function analysis was conducted to generate a classification matrix and determine overall accuracy of the TTM constructs to predict the participants' stage of change for exercise classification. Multivariate F-tests along with post-hoc analyses were performed to identify the differences in perceived benefits /barriers. In addition, correlation analysis was carried out to explore the correlations of the stages of exercise behavior with perceived benefits /barriers.

\section{Result}

Descriptive statistics and result of correlation analysis. Table 1 indicates the sample's means and standard deviations for each item of the benefits and barriers sub-scales. And this sample of urban residents felt significantly higher perceived benefits $(M=2.88, S D=0.71)$ than barriers $(\mathrm{M}=2.16, \mathrm{SD}=0.808)$ to exercise $(\mathrm{t}=9.01, \mathrm{p}<0.001)$.

Table 1. Exercise Benefits/Barriers Scale: Mean and Standard Deviation of Each Questionnaire Item.

\begin{tabular}{cccc}
\cline { 2 - 4 } & M (SD) & & M (SD) \\
\hline Physical Performance & $3.04(.682)$ & Physical Exertion & $2.36(.727)$ \\
Psychological Outlook & $2.92(.727)$ & Exercise Milieu & $2.17(.850)$ \\
Life Enhancement & $2.82(.638)$ & Time Expenditure & $2.08(.719)$ \\
Social Interaction & $2.75(.765)$ & Family Discouragement & $1.80(.750)$ \\
Preventative Health & $2.68(.763)$ & All sub-scales & $2.16(.808)$ \\
All sub-scales & $2.88(.710)$ & & \\
\hline
\end{tabular}

Classification into stage of change. According to the samples, the distribution of the stages of exercise behavior change is that $40(12.50 \%)$ individuals reported being in pre-contemplation, 67(20.94\%) in contemplation, 84(26.25\%) in preparation, 93(29.06\%) in action and 36(11.25\%) in maintenance. The means and standard deviations for the benefits and barriers subscales at each stage of change are shown in Table 2.

Table 2. Means and Standard Deviations for Benefits and Barriers Subscales by Stage of Change

\begin{tabular}{cccccc}
\hline & Pre-contemplation & contemplation & Preparation & Action & Maintenance \\
\hline Benefit-subscale & & & & & \\
\hline $\begin{array}{c}\text { Physical } \\
\text { Performance }\end{array}$ & $2.52(.838)$ & $3.05(.703)$ & $3.14(.543)$ & $3.05(.510)$ & $3.44(.636)$ \\
$\begin{array}{c}\text { Psychological } \\
\text { Outlook }\end{array}$ & $2.37(.893)$ & $2.93(.692)$ & $3.00(.641)$ & $2.89(.500)$ & $3.41(.656)$ \\
$\quad$ Life & & & & & \\
Enhancement & $2.41(.833)$ & $2.73(.555)$ & $2.77(.575)$ & $2.91(.504)$ & $3.26(.686)$ \\
$\quad$ Social & $2.33(.990)$ & $2.53(.703)$ & $2.89(.624)$ & $2.86(.614)$ & $3.30(.701)$ \\
\hline
\end{tabular}




\begin{tabular}{cccccc}
\hline $\begin{array}{c}\text { Interaction } \\
\text { Preventative } \\
\text { Health }\end{array}$ & $2.51(.920)$ & $2.61(.738)$ & $2.65(.620)$ & $2.69(.748)$ & $3.21(.857)$ \\
\hline Barrier-subscale & & & & & \\
\hline $\begin{array}{l}\text { Physical } \\
\text { Exertion }\end{array}$ & $2.44(.943)$ & $2.40(.703)$ & $2.24(.628)$ & $2.38(.606)$ & $2.52(.834)$ \\
$\begin{array}{c}\text { Exercise Milieu } \\
\text { Time }\end{array}$ & $1.97(.827)$ & $2.20(.797)$ & $2.18(.837)$ & $2.29(.919)$ & $2.23(.862)$ \\
$\begin{array}{c}\text { Expenditure } \\
\text { Family }\end{array}$ & $2.40(.837)$ & $2.10(.644)$ & $1.95(.641)$ & $1.90(.627)$ & $2.24(.936)$ \\
Discouragement & $2.17(.950)$ & $1.95(.946)$ & $1.70(.645)$ & $1.52(.593)$ & $1.47(.567)$ \\
\hline
\end{tabular}

The exercise benefits/barriers and stage of change. The relationship between the perceived benefits/barriers and the stages of change to exercise was explored. Table 3 displays the correlation-matrix between perceived benefits/barriers and stage of change to exercise.

Table 3. Correlation-matrix for Perceived Benefits/Barriers and Stage of Change

\begin{tabular}{cccccc}
\hline & Pre-contemplation & contemplation & Preparation & Action & Maintenance \\
\hline Physical Performance & $-.272^{* *}$ & -.012 & $.075^{*}$ & .025 & $.184^{* *}$ \\
Psychological Outlook & .012 & $.079^{*}$ & $-.304^{* *}$ & .018 & $.228^{* *}$ \\
Life Enhancement & $-.183^{* *}$ & -.022 & -.030 & $.069^{*}$ & $.207^{* *}$ \\
Social Interaction & -.090 & .062 & $-.177^{* *}$ & $.187^{* *}$ & $.243^{* *}$ \\
Preventative Health & -.058 & $-.217^{* *}$ & -.031 & $.083^{*}$ & $.234^{* *}$ \\
Physical Exertion & $.117^{*}$ & -.109 & -.051 & -046 & $-.131^{*}$ \\
Exercise Milieu & .029 & .021 & $-.120^{*}$ & $-.099^{*}$ & -.046 \\
Time Expenditure & $.181^{* *}$ & -.104 & -.017 & -.018 & $-.122^{*}$ \\
Family & .028 & $.119^{*}$ & .003 & -.113 & -.008 \\
Discouragement & **. Correlation is significant at the 0.01 level (2-tailed). & \\
\hline & *. Correlation is significant at the 0.05 level (2-tailed). &
\end{tabular}

\section{Discussion}

Studies on the analysis of overall level of exercise benefits and barrier cognition show that individuals marked Agree or Very Agree to most of the benefits of physical exercises, but showed lower agreement on the exercise barriers. This means, though residents haven't formed a habit of exercising regularly, they are fully aware of the benefits of exercises. Therefore, in view of the influencing factors of individuals' not participating physical exercises, exercise barriers have far more influences than exercise benefits, which is coincide with the previous study results(Nahas \& Goldfine, 2010)[5] In the study, respondents regarded physical performance as the most beneficial factor $(p<0.05)$, such as muscle strength, body balance and body shape etc. On the other hand, the respondents also believed that the biggest exercise barrier lies in physical exertion $(\mathrm{p}<0.05)$, followed by exercise milieu and time expenditure.

In the analysis of various exercising stages, benefits and barriers, studies show that individual participation of action and maintenance stage are positively correlated with exercise benefit scaling, but negatively with exercise barrier scaling. The study results found that at pre-contemplation stage of individuals participating exercises, though people are much aware of the benefits of exercises on physical performance and life enhancement $(\mathrm{p}<0.01)$, the correlation between psychological outlook and social interaction scale is not distinct. Moreover, the correlation also shows that the obvious scaling often lies in personal factors such as: physical power consumption and time etc. According to the Theory of Motivation, social interaction is one of the key motivations of individuals keeping participating exercises. Therefore, the study shows at the pre-contemplation stage of individuals participating exercises, the individuals' internal factor or exercising motivation is the major reason to change their exercise behaviors which provides a new direction for early exercise intervention. 
Besides, the barrier factor of exercise milieu is only more distinctive at preparation stage and action stage, but less at maintenance stage. In the previous studies of the relationship between exercise motivation and physical exercise stage, researchers proved that external motivation works more at action stage and works less at maintenance stage [6-9]. Therefore, external motivations such as exercise environment can change individuals' behavior in a short time, but they are not the determinants in maintenance for a long time[10,11]. On the contrary, personal factors such as physical exertion and time expenditure are closely related with individuals' persistence in exercise $(\mathrm{p}<0.05)$.

In conclusion, the factors influencing individuals' exercise participation vary at different stages, so exercise intervention methods should be changeable to fit the individual needs and exercise stages. The baseline data are used to study the correlation between different exercise stages, benefits and barrier cognition, and the correlation varies as time and exercise forms change. Therefore, further studies are needed on the research and analysis of longitudinal data from the introduction of intervention methods.

\section{References}

[1] Craig, R.J.M.: The Health and Social Care Information Centre (2009).

[2] El Ansari,W. \& Phillips, C.J.:The Costs and benefits of participants in community partnerships.Vol. 5(2004) No. 1,p.35-48.

[3] Lovell G. P., EI Ansari, W. \& Parker, J. K.: International Journal of Environmental Research and Public Health, Vol. 3(2010) No. 7,p. 784-798.

[4] Tang, G. \&, Cong H.: Chinese Sports Science and Technology, Vol. 45(2009) No. 1,p.139-143.

[5] Nahas, M.V. \& Goldfine, B: Phys. Educator, Vol. 60(2010) No. 1,p.42-57.

[6] Ingledew, D. K., Markland, D. \& Medley, A. R.: Journal of Health Psychology, Vol. 4(1998) No. 3,p.477-489.

[7] Janz, N.K.\& Becker, M.H.: Health Education Q. Vol. 11(1984) No. 1,p.1-47.

[8] Sechrist, K.R., Walker, S, N, \& Pender, N, J..: Research in Nursing \& Health,Vol. 10(1987) No. 6,p.357-365.

[9] Oka, K.: Japanese Journal of Health Promotion, (2003) No. 1,p.15-22.

[10] Sorensen, M.\&Gill, D. L.:Scandinavian Journal of Medicine \& Science in Sports, Vol. 15(2010) No. 5,p.651-663.

[11]Vaughn,S.: Rehabilitation Nursing, Vol. 34(2009) No. 1,p.17-23. 